\title{
Stabilization of circulating tumor cells in blood using a collection device with a preservative reagent
}

\author{
Jianbing Qin ${ }^{1 *}$, Jodi R Alt ${ }^{1}$, Bradford A Hunsley ${ }^{1}$, Thomas L Williams ${ }^{2}$ and M Rohan Fernando ${ }^{1 *}$
}

\begin{abstract}
Background: The enumeration and characterization of circulating tumor cells (CTCs) in the blood of cancer patients is useful for cancer prognostic and treatment monitoring purposes. The number of CTCs present in patient blood is very low; thus, robust technologies have been developed to enumerate and characterize CTCs in patient blood samples. One of the challenges to the clinical utility of CTCs is their inherent fragility, which makes these cells very unstable during transportation and storage of blood samples. In this study we investigated Cell-Free DNA $\mathrm{BCT}^{\mathrm{TM}}(\mathrm{BCT})$, a blood collection device, which stabilizes blood cells in a blood sample at room temperature (RT) for its ability to stabilize CTCS at RT for an extended period of time.

Methods: Blood was drawn from each donor into $\mathrm{K}_{3}$ EDTA tube, CellSave tube and BCT. Samples were then spiked with breast cancer cells (MCF-7), transported and stored at RT. Spiked cancer cells were counted using the Veridex CellSearch ${ }^{\mathrm{TM}}$ system on days 1 and 4 . The effect of storage on the stability of proteins and nucleic acids in the spiked cells isolated from $\mathrm{K}_{3}$ EDTA tube and BCT was determined using fluorescence staining and confocal laser scanning microscopy.
\end{abstract}

Results: MCF-7 cell recovery significantly dropped when transported and stored in $\mathrm{K}_{3}$ EDTA tubes. However, in blood collected into CellSave tubes and BCTs, the MCF-7 cell count was stable up to 4 days at RT. Epithelial cell adhesion molecule (EpCAM) and cytokeratin (CK) in MCF-7 cells isolated from BCTs was stable at RT for up to 4 days, whereas in MCF-7 cells isolated from $\mathrm{K}_{3}$ EDTA blood showed reduced EPCAM and CK protein expression. Similarly, BCTs stabilized c-fos and cyclin D1 mRNAs as compared to $K_{3}$ EDTA tubes.

Conclusion: Cell-Free DNA ${ }^{\text {TM }}$ BCT blood collection device preserves and stabilizes CTCs in blood samples for at least 4 days at RT. This technology may facilitate the development of new non-invasive diagnostic and prognostic methodologies for CTC enumeration as well as characterization.

Keywords: Circulating tumor cells, Blood collection devices, Clinical laboratory techniques

\section{Background}

In the peripheral blood of patients with solid tumors of epithelial origin, some circulating cells have been found that have characteristics of tumor cells [1]. These cells that are present in the bloodstream of cancer patients, known as circulating tumor cells (CTCs), are thought to play an important role in cancer metastasis by breaking loose from a solid tumor, entering the circulation, and then migrating to distant organs to develop secondary

\footnotetext{
* Correspondence: jain@streck.com; rfernando@streck.com ${ }^{1}$ R\&D Division, Streck, Inc., 7002 S 109 Street, La Vista, NE 68128, USA Full list of author information is available at the end of the article
}

tumors. The presence of CTCs in blood has been known for more than a century [2]. However, the clinical utility of CTCs was first shown in patients with metastatic breast cancer by Cristofanilli and colleagues [3]. The patient survival prognosis was more favorable with the identification of $<5$ CTCs per $7.5 \mathrm{~mL}$ blood. CTCs are detectable in the blood of patients with metastatic cancer using different technologies [4]. Since CTCs are rare they need to be enriched from patient blood for accurate enumeration and characterization [5,6]. Most of the CTC enrichment and identification assays available today are based on enrichment with anti-EpCAM antibodies and

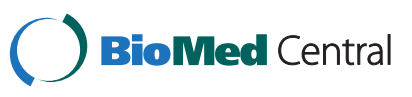

(c) 2014 Qin et al.; licensee BioMed Central Ltd. This is an Open Access article distributed under the terms of the Creative Commons Attribution License (http://creativecommons.org/licenses/by/2.0), which permits unrestricted use, distribution, and reproduction in any medium, provided the original work is properly credited. 
subsequent identification using anti-CK antibodies $[7,8]$. An example is the CellSearch ${ }^{\text {th }}$ instrument system, a clinically validated system cleared by the USA Food and Drug Administration for isolation and enumeration of CTCs in blood of patients with metastatic breast, prostate and colorectal cancer [3,9].

There is a growing interest in the use of CTCs in noninvasive diagnosis, prognosis and monitoring of treatment regimens. The low abundance of the CTCs and their fragile nature may introduce variability in the evaluation of CTCs using different assay platforms. This fragile nature of CTCs arises due to the apoptosis of CTCs which begins after separation from the tumor of origin and after removal of blood from patient [9-11]. Therefore, it is necessary to address several pre-analytical issues that arise during the time between blood draw and CTC enrichment and characterization in order to effectively preserve CTCs for analysis. These include delays in blood processing, blood storage temperature, and agitation of the sample during transport and shipment of blood. Such conditions may affect the integrity of already fragile CTCs causing accurate enumeration and characterization of CTCs difficult. As a result, it is important to consider the type of blood collection device and post-phlebotomy conditions while working with CTC samples. Previous studies have shown that blood collection devices with cellular preservatives are capable of stabilizing CTCs for up to 96 hours [11-13].

Cell-Free DNA BCT ${ }^{\mathrm{m}}$ is a blood collection device with a formaldehyde free stabilization reagent [14] that preserve cell-free DNA in a blood sample for up to 14 days at RT $[15,16]$. It does so by stabilizing nucleated blood cells in blood and preventing cellular DNA release into plasma [17]. This study was designed to investigate the effectiveness of this blood collection device for the stabilization of CTCs in blood sample for an extended period of time at RT.

\section{Results}

\section{Recovery of spiked MCF-7 cells in blood}

Experiments were designed to determine the ability of BCTs to stabilize CTCs during blood sample storage and transportation compared to standard $\mathrm{K}_{3}$ EDTA and CellSave blood collection tubes. Parallel blood samples drawn into $K_{3}$ EDTA, CellSave and BCTs spiked with MCF-7 cells were analyzed using CellSearch system for spiked tumor cell recovery. As shown in Figure 1, BCTs and CellSave tubes demonstrated stable percentage recovery of the tumor cells at RT for up to 4 days. In BCTs, at day 1 $60 \%$ (Standard deviation $(\mathrm{SD})=4 \%$, coefficient of variation $(\mathrm{CV})=7.3 \%)$ of spiked MCF-7 cells were recovered and at day 4 it was $58 \%(\mathrm{SD}=8 \%, \mathrm{CV}=14.3 \%)$. Similarly, in CellSave tubes at day $152 \%$ (Standard deviation (SD) $=5 \%$, coefficient of variation $(\mathrm{CV})=10.2 \%$ ) of spiked MCF-7 cells

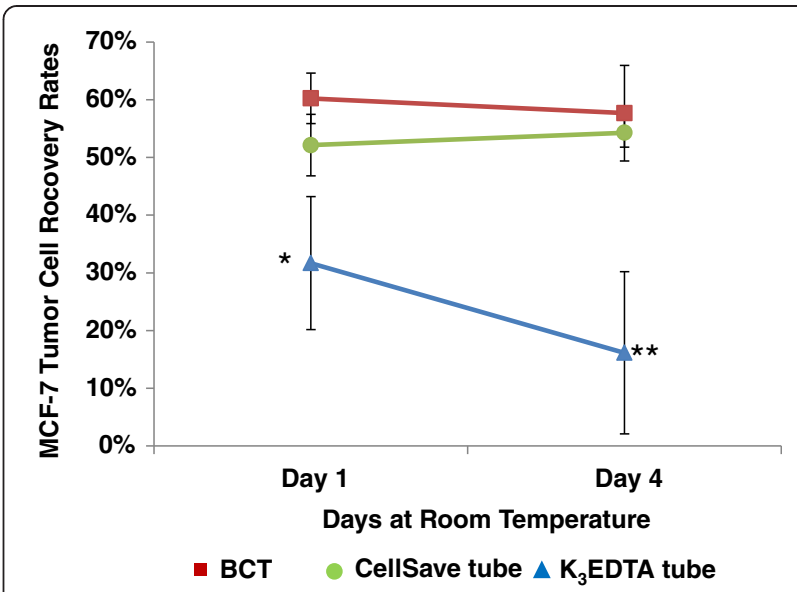

Figure 1 Recovery of spiked MCF-7 cells in blood. Normal donor blood was drawn into $\mathrm{K}_{3}$ EDTA tubes, CellSave tubes and BCTs and a known number of breast tumor cells (MCF-7) were spiked. The whole blood samples were analyzed on CellSearch system to determine recovery of spiked MCF-7 cells at indicated time points. The tumor cell recovery from BCTs (red square symbol) and CellSave tubes (green circle symbol) was stable and much higher than from $\mathrm{K}_{3}$ EDTA (blue triangle symbol) tubes after the blood samples were transported and stored at RT for 4 days. Samples drawn into $K_{3}$ EDTA tubes that were transported and stored at RT showed a statistically significant decrease in CTC count when compared to samples transported in the BCT and CellSave $\left({ }^{*} P<0.001,{ }^{* *} P<0.0003\right)$. Error bars indicate standard deviation, $n=7$.

were recovered and at day 4 it was $54 \%(\mathrm{SD}=2 \%, \mathrm{CV}=$ $4.6 \%)$. In contrast, $K_{3}$ EDTA tubes failed to preserve CTCs resulting in a much lower recovery rates for both day 1 and 4 as compared to BCTs. In $K_{3}$ EDTA tubes, at day 1 , recovery rate was $32 \%(\mathrm{SD}=12 \%, \mathrm{CV}=36.3 \%)$ of the spiked MCF-7 cells and at day 4 it was $16 \%$ (SD = $14 \%, \mathrm{CV}=87 \%$ ).

\section{Stability of EpCAM and CK proteins by immunofluorescence}

Figure 2 illustrates the effects of RT storage on the stability of tumor-associated trans-membrane protein EpCAM and cytoskeleton protein CK of MCF-7 tumor cells spiked into blood plasma. The EpCAM protein (green fluorescence) was stable up to 4 days at RT in BCTs whereas in $\mathrm{K}_{3}$ EDTA tubes this membrane protein was partially degraded by day 4 as evidenced from the weak and diffused fluorescence signal for EpCAM cell membrane protein. The CK protein signal (red fluorescence) appears to be unchanged in BCTs up to 4 days. However, the reduced fluorescence intensity for this protein in spiked MCF-7 cells recovered from $\mathrm{K}_{3}$ EDTA tubes suggests it was less stable than the BCT samples. When cells were stained with DAPI, the nucleus and nuclear content appear unchanged in cells recovered from BCTs but not cells recovered from $\mathrm{K}_{3}$ EDTA tubes after 4 days of RT storage. 


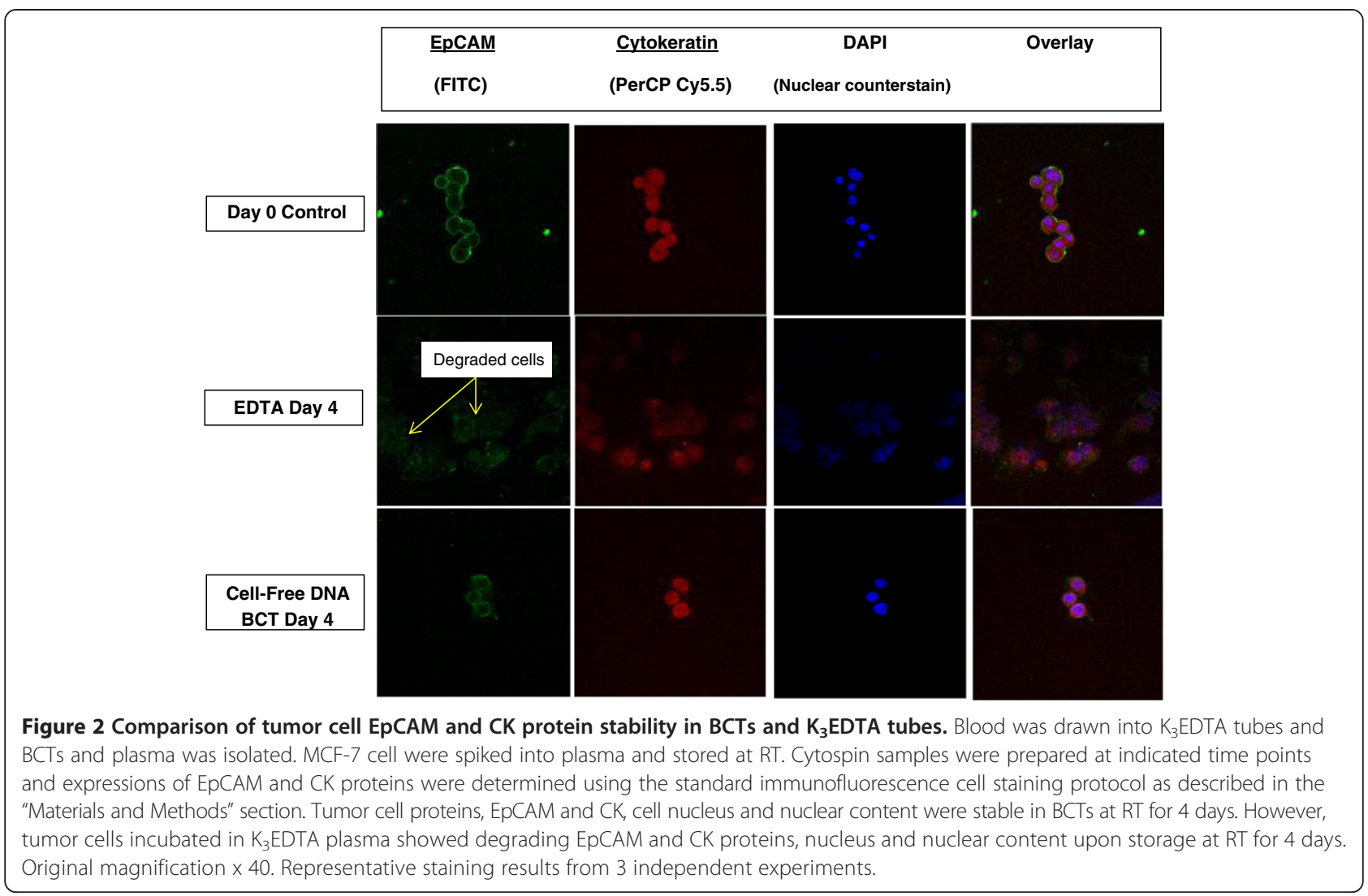

\section{Stability of mRNA molecules using molecular beacons}

Experiments were performed to study the stability of mRNA in the spiked MCF-7 cells recovered from BCTs and $\mathrm{K}_{3}$ EDTA tubes. Slides of the recovered MCF-7 cells were prepared as described above. To detect mRNA in situ, fluorescent-labeled molecular beacons and a scanning confocal microscope were used. As shown in Figure 3, c-fos mRNA (green fluorescence) and cyclin D1 mRNA (red fluorescence) showed similar intensity in cells on day 0 and day 4 when stored in BCTs. However in $K_{3}$ EDTA samples $c$-fos mRNA signal was reduced after 4 days of storage at RT, suggesting that c-fos mRNA expression was degraded or downregulated. There was slight increase in cyclin D1 mRNA level in MCF-7 cells recovered from $K_{3}$ EDTA tube after 4 days of incubation at RT.

\section{Discussion}

The presence of CTCs in patients with cancer has been known for over a century [2]. However, utilization of these rare cells in cancer diagnosis and prognosis was not feasible since methodologies to detect, isolate and characterize CTCs have not been developed until recently. With the development of robust methodologies to enrich, isolate and characterize CTCs in different types of solid organ cancers, several clinical studies have now been conducted to investigate the possible use of CTCs in cancer diagnosis and prognosis [3,18]. Assays that enumerate CTCs using the CellSearch system have been developed as an aid to monitor patients with metastatic breast, colorectal, and prostate cancers $[3,19,20]$. The potential usefulness of CTC enumeration has also been demonstrated with melanoma, urothelial, and lung cancer [21-23].

Factors that limit the utility of CTCs in cancer diagnosis and prognosis are the low abundance and the fragility of the CTCs. These factors may introduce variability in the evaluation of CTCs using different assay platforms [24]. Transportation of blood samples from the site of phlebotomy to another facility is commonly required for CTC enumeration and characterization. During postphlebotomy blood sample transportation and storage, fragile CTCs may degrade further compromising the accuracy of CTC enumeration and characterization [11-13]. In our study, we have minimized CTC degradation with a novel cell stabilizing reagent contained within a blood collection tube.

In our experiment described in Figure 1, we modeled transportation as well as storage effects on CTCs in blood samples. We spiked 2000 MCF-7 cells into blood contained in standard $\mathrm{K}_{3}$ EDTA and CellSave tubes or the novel BCTs. These samples were then shipped from 


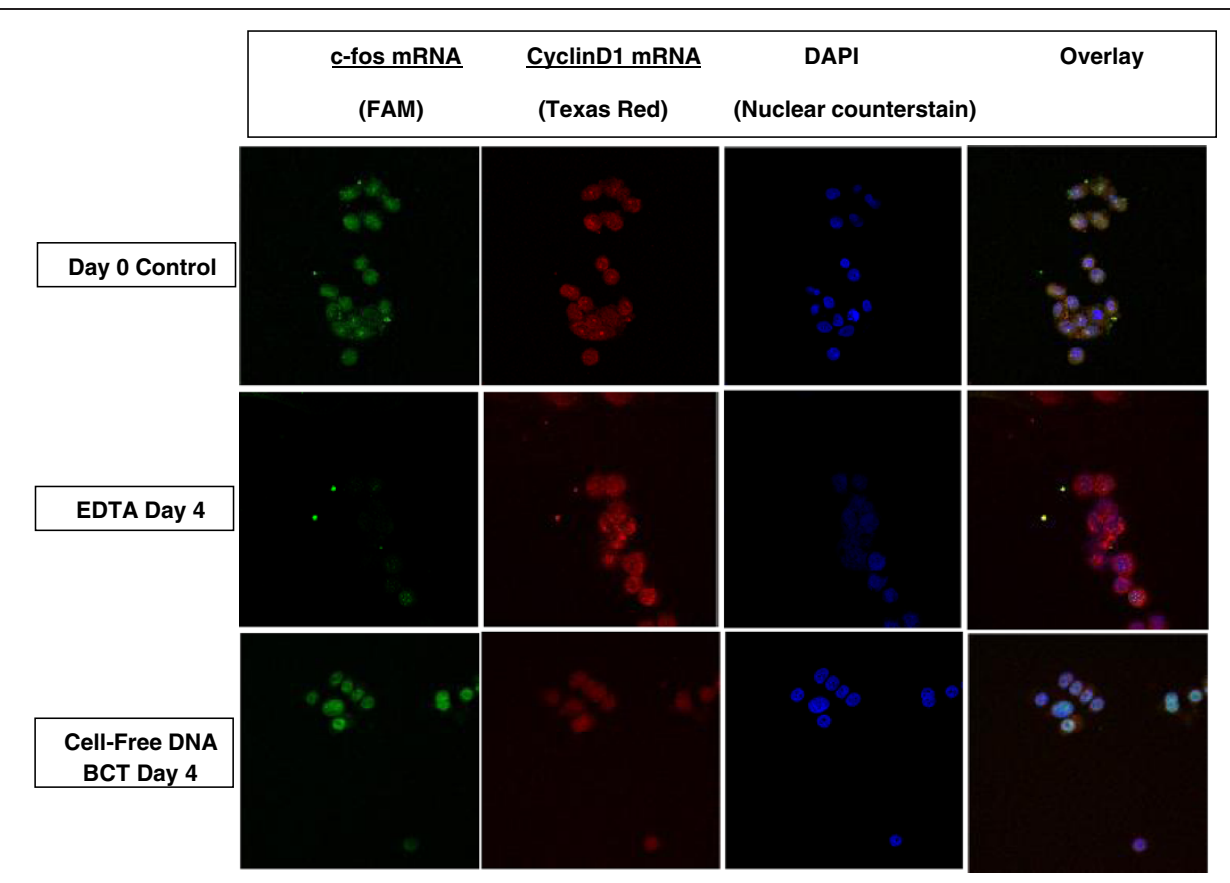

Figure 3 Comparison of tumor cell mRNA stability in BCTs and $K_{3}$ EDTA tubes. MCF-7 cells spiked into $K_{3}$ EDTA and BCT plasma were isolated at indicated time points and cytospin samples were prepared as described in the "Materials and Methods" section. MCF-7 cells on cytospin were stained with fluorescent-labeled molecular beacons for c-fos (green fluorescence) and cyclin D1 (red fluorescence) mRNAs. The confocal microscopic images show that c-fos and cyclin D1 mRNA levels did not change in tumor cells incubated in plasma from BCT at RT for 4 days. However, tumor cells incubated in $\mathrm{K}_{3}$ EDTA plasma for 4 days at RT showed a decrease in fluorescence for c-fos mRNA compared to day 0 fluorescence but cyclin D1 mRNA showed a slight increase upon storage at RT for 4 days. Original magnification $\times 40$. Representative staining results from 3 independent experiments.

Omaha, NE to Maryville, TN for analysis by the CellSearch system. Our CTC recovery study conducted using spiked MCF-7 cells provides evidence that BCTs are able to preserve CTCs during transportation and storage at RT for up to 4 days, similar to CellSave tube which is an integral part of CellSearch System. Previous studies using the CellSearch have shown that the recovery rate for MCF-7 cells is between $62-89 \%$ [25]. Our results show that BCTs, post shipping day 1 and day 4 , had recovery rates of $61 \%$ and $57 \%$, respectively. There was no statistically significant difference between these two values indicating that CTCs are stable in BCTs for 4 days after shipping at RT. However, in $\mathrm{K}_{3}$ EDTA tubes, CTC recovery rate was very low compared to BCTs. The $\mathrm{K}_{3}$ EDTA tubes from the same study showed day 1 and day 4 recovery rates of $32 \%$ and $16 \%$. There was a statistically significant decrease in CTC recovery in $\mathrm{K}_{3} \mathrm{EDTA}$ tube between day 1 and day 4 compared to BCTs.

As shown in Figure 2, immunofluorescence staining of recovered CTCs for EPCAM and CK showed stability of these proteins from BCTs after 4 days of RT storage. However, cells recovered from $\mathrm{K}_{3}$ EDTA tubes showed degrading EpCAM and CK proteins after 4 days under the same conditions. DAPI staining of cells showed stable nucleus and nuclear content in CTCs recovered from BCTs whereas CTCs recovered from $\mathrm{K}_{3}$ EDTA tubes showed degrading nucleus and nuclear content. Our molecular beacon study (Figure 3) shows that both c-fos and cycling D1 mRNA are stable in BCTs at RT for up to 4 days. The stability of both c-fos and cyclin D1 mRNAs in BCT may results from the stabilization of tumor cells by the stabilizing reagent present in the $\mathrm{BCT}$.

However, CTCs incubated in $\mathrm{K}_{3}$ EDTA plasma for 4 days at RT showed almost complete degradation of c-fos mRNA whereas cyclin D1 mRNA level was slightly increased. We speculate that in degrading MCF-7 cells, c-fos gene may be down-regulated and cyclin D1 gene may be up-regulated.

Analysis of the stabilizing reagent present in BCT device by ${ }^{13} \mathrm{C}$-NMR has shown that the reagent is free of formaldehyde [14]. Aldehyde based chemicals traditionally used in cell stabilization, such as formaldehyde and glutaraldehyde, are known to damage DNA and RNA by causing chemical modifications in nucleic acids [26]. Application of such aldehyde based chemicals for CTC stabilization may cause problems for CTC characterization studies. Cell stabilizing reagent present in BCTs has an advantage over aldehyde based stabilizing agents because it has no negative effect on DNA amplification by PCR [27]. 


\section{Conclusions}

In this study, we have modeled various circumstances that could alter CTC detection on an FDA cleared instrument running assays that are designed to be helpful in cancer diagnosis, prognosis and the monitoring of patient response to treatments. The modeling of postphlebotomy has shown that $\mathrm{BCT}$ provides preservation and stabilization of CTCs in blood samples for up to 4 days at $\mathrm{RT}$ while a standard $\mathrm{K}_{3}$ EDTA tube does not. By using BCT for future studies, it could facilitate the development of new non-invasive diagnostic and prognostic methodologies for CTC enumeration as well as characterization.

\section{Materials and methods Blood sample collection}

This study was approved by the institutional review board of the Methodist Hospital, Omaha, NE, USA, and informed consent was obtained from all donors prior to blood draw. Blood specimens were collected from apparently healthy adult donors by standard phlebotomy techniques.

\section{Cell culture}

Breast cancer cell line, MCF-7, was obtained from American Type Culture Collection (Rockville, MD, USA) and routinely passaged in Eagle's MEM medium containing $10 \%$ fetal bovine serum at $37 \mathrm{C}$ in humidified atmosphere of $5 \% \mathrm{CO}_{2}$.

\section{Recovery of spiked MCF-7 cells in blood}

For MCF-7 cell spiking experiments, blood from each donor (7 donors in total) was drawn into two $10 \mathrm{~mL}$ $\mathrm{K}_{3}$ EDTA tubes (BD Vacutainer $^{\circ}$, Becton Dickinson, Franklin Lakes, NJ, USA), two $10 \mathrm{~mL}$ CellSave tubes (Veridex, North Raritan, NJ, USA) and two $10 \mathrm{~mL}$ BCTs (Streck Inc., Omaha, NE, USA). A known number of MCF-7 cells (2000 cells/10 mL of whole blood) were then spiked into each tube and the samples were mixed immediately by inverting 10 times each. All samples were shipped at ambient temperature to Geneuity Clinical Research Services (Maryville, TN, USA). The samples were analyzed on days 1 and 4, post phlebotomy, on the Veridex CellSearch system in order to count the recovery rate of the MCF-7 cells. Blood samples were maintained at RT during the entire process.

\section{Detection of EpCAM and CK by immunofluorescence cell staining}

Blood was drawn from each donor into one $10 \mathrm{~mL}$ $\mathrm{K}_{3}$ EDTA tube and one $10 \mathrm{~mL}$ BCT. Plasma was separated from blood within $2 \mathrm{~h}$ post collection. To separate plasma, blood samples were centrifuged at $300 \times g$ for $20 \mathrm{~min}$ at RT. The upper plasma layer was carefully removed without disturbing the buffy coat and transferred to a fresh tube and centrifuged again at $5000 \times g$ for $10 \mathrm{~min}$. MCF-7 cells $(\approx 2,000$ cells $/ 4-5 \mathrm{~mL}$ of plasma) were spiked into the cell-free plasma and stored at RT. On days 0 and 4, MCF-7 cells were centrifuged at $500 \mathrm{rpm}$ for $7 \mathrm{~min}$ on glass slides using Shandon Cytospin $^{\circ} 3$ cytocentrifuge. Slides were dried and immunostained with a primary antibody cocktail containing a mouse anti-EpCAM antibody (VU-1D9, \#sc-51681, 1:100) and a mouse anti-CK antibody (T-13, \#sc-241376, 1:100). After $1 \mathrm{~h}$ of incubation, slides were washed twice with PBS and probed with fluorescent labeled secondary antibodies for mouse anti-EpCAM (donkey anti-mouse IgG-FITC, \#sc-2099, 1:200) and mouse anti-CK (donkey anti-goat IgG-PerCP-Cy5.5, \#sc-45102, 1:200) antibodies for $1 \mathrm{~h}$. After again washing slides two times with PBS, coverslips were mounted onto slides with UltraCruz ${ }^{\mathrm{Tm}}$ mounting medium (\#sc-24941) containing 4', 6-diamidino2-phenylindole (DAPI) to counterstain cell nuclei. All antibodies and mounting medium were purchased from Santa Cruz Biotechnology, Inc. (Dallas, TX, USA) and manufacturer's protocol was followed. Fluorescent images were obtained using Zeiss LSM 510 META NLO laser scanning confocal microscope (Oberkochen, Germany).

\section{In situ detection of mRNA using molecular beacons}

Cytospin slides of MCF-7 cells in cell-free plasma were prepared as described above. Cells on the slides were fixed and permeabilized with ice cold methanol $\left(-10^{\circ} \mathrm{C}\right)$ for $10 \mathrm{~min}$. After air drying, slides were stained with a mixture of $200 \mathrm{nmol} / \mathrm{L}$ of fluorescent-tagged molecular beacons targeting c-fos or cyclin D1 mRNAs in OptiMEM (Invitrogen) at $37^{\circ} \mathrm{C}$ for $1 \mathrm{~h}$. Slides were washed, countstained with DAPI and examined using a confocal microscope. The sequences of molecular beacons are 5'-6-FAM-CGACCTCTAGTTGGTCTGTCTCCGCGG TGG-Dabcyl-3' for c-fos and 5'-Texas-Red-TGGAGT TGTCGGTGTAGACTCCA-Dabcyl-3' for cyclin D1, which were purchased from Eurofins MWG Operon (Huntsville, AL).

\section{Statistical analysis}

Statistical analysis was carried out using Microsoft Excel for Office 2007. Analysis was performed using paired, two tailed Student's $t$-test and $\mathrm{p}<0.05$ was considered statistically significant.

\section{Abbreviations}

CTC: Circulating tumor cell; BCT: Cell-Free DNA ${ }^{\mathrm{TM}}$ BCT; RT: Room temperature; EpCAM: Epithelial cell adhesion molecule; CK: Cytokeratin.

\section{Competing interests}

TW declares that no conflicts of interest exist. All other authors are full time employees of Streck Inc. 


\section{Authors' contributions}

JQ participated in the experimental design, performed the laboratory work, carried out data and statistical analyses, interpreted the results, prepared and revised the manuscript. JRA participated in experiment optimization and revised the manuscript. BAH coordinated the CellSearch study and revised the manuscript. TW was responsible for IRB of blood sample collection, reviewed the manuscript. MRF conceived the study, participated in its design and the laboratory work, interpreted the results, prepared and revised the manuscript. All authors have read and approved the final manuscript.

\section{Acknowledgement}

We the authors gratefully acknowledge the technical assistance provided by Gary Krzyzanowski We also thank Joel M. Lechner for helpful discussions and critical reading of the manuscript; Kitty M. McCarthy and Catherine J. Horstman for helping with cytospin preparations; John B. Billheimer and Dr. Richard Hallworth (Integrated Biomedical Imaging Facility, Creighton University, Omaha, NE, USA) for helping with confocal microscopy.

\section{Author details}

'R\&D Division, Streck, Inc., 7002 S 109 Street, La Vista, NE 68128, USA.

${ }^{2}$ Methodist Hospital Laboratory, 8303 Dodge Street, Omaha, NE 68114, USA.

Received: 24 July 2013 Accepted: 28 February 2014

Published: 7 March 2014

\section{References}

1. Ring A, Smith IE, Dowsett M: Circulating tumor cells in breast cancer. Lancet 2004, 5:79-88.

2. Ashworth TR: A case of cancer in which cells similar to those in the tumors were seen in the blood after death. Aust Med J 1869, 14:146-149

3. Cristofanilli M, Budd GT, Ellis MJ, Stopeck A, Matera J, Miller MC, Reuben JM, Doyle GV, Allard WJ, Terstappen LW, Hayes DF: Circulating tumor cells, disease progression, and survival in metastatic breast cancer. New Engl J Med 2004, 91:781-791.

4. Fehm T, Solomayer EF, Meng S, Tucker T, Lane N, Wang J, Gebauer G: Methods for isolating circulating epithelial cells and criteria for their classification as carcinoma cells. Cytotherapy 2005, 7:171-185.

5. Tibbe AG, Miller MC, Terstappen LW: Statistical considerations for enumeration of circulating tumor cells. Cytometry A 2007, 71:154-162.

6. Nagrath S, Sequist LV, Maheswaran S, Bell DW, Irimia D, Ulkus L, Smith MR, Kwak EL, Digumarthy S, Muzikansky A, Ryan P, Balis UJ, Tompkins RG, Haber $D A$, Toner M: Isolation of rare circulating tumor cells in cancer patients by microchip technology. Nature 2007, 450:1235-1239.

7. Dong X, Alpaugh RK, Cristofanilli M: Circulating tumor cells (CTCs) in breast cancer: a diagnostic tool for prognosis and molecular analysis. Chin J Cancer Res 2012, 24:388-98.

8. Deng G, Herrler M, Burgess D, Manna E, Krag D, Burke JF: Enrichment with anti-cytokeratin alone or combined with anti-EpCAM antibodies significantly increases the sensitivity for circulating tumor cell detection in metastatic breast cancer patients. Breast Cancer Res 2008, 10:2131-2141.

9. Allard WJ, Matera J, Miller MC, Repollet M, Connelly MC, Rao C, Tibbe AG, Uhr JW, Terstappen LW: Tumor cells circulate in the peripheral blood of all major carcinomas but not in healthy subjects or patients with nonmalignant disease. Clin Cancer Res 2004, 10:6897-6904.

10. Meng S, Tripathy D, Frenkel EP, Shete S, Naftalis EZ, Huth JF, Beitsch PD, Leitch M, Hoover S, Euhus D, Haley B, Morrison L, Fleming TP, Herlyn D, Terstappen LW, Fehm T, Tucker TF, Lane N, Wang J, Uhr JW: Circulating tumor cells in patients with breast cancer dormancy. Clin Cancer Res 2004, 10:8152-8162.

11. Smerage JB, Doyle GV, Budd GT, Schott AF, Blayney DW, Wicha MS, Repollet M, Terstappen LWMM, Hayes DF: The detection of apoptosis and Bcl-2 expression in circulating tumor cells (CTCs) from women being treated for metastatic breast cancer [abstract]. Proc Am Assoc Cancer Res 2006, 47:\#792.

12. Riethdorf S, Fritsche H, Müller V, Rau T, Schindlbeck C, Rack B, Janni W, Coith C, Beck K, Jänicke F, Jackson S, Gornet T, Cristofanilli M, Pantel K: Detection of circulating tumor cells in peripheral blood of patients with metastatic breast cancer: a validation study of the cell search system. Clin Cancer Res 2007, 13:920-928.
13. Lianidou ES, Markou A: Circulating tumor cells in breast cancer: detection systems, molecular characterizations, and future challenges. Clin Chem 2011, 57:1242-1255.

14. Das K, Dumais J, Basiaga S, Krzyzanowski GD: Carbon-13 nuclear magnetic resonance analyses of formaldehyde free preservatives. Acta Histochem 2013, 115:481-6.

15. Fernando MR, Chen K, Norton S, Krzyzanowski G, Bourne D, Hunsley B, Ryan WL, Bassett $C$ : A new methodology to preserve the original proportion and integrity of cell-free fetal DNA in maternal plasma during sample processing and storage. Prenat Diagn 2010, 30:418-424.

16. Norton SE, Luna KK, Lechner JM, Qin J, Fernando MR: A new blood collection device minimizes cellular DNA release during sample storage and shipping when compared to a standard device. J Clin Lab Anal 2013, 27:305-311.

17. Norton SE, Lechner JM, William T, Fernando MR: A stabilizing reagent prevents cell-free DNA contamination by cellular DNA in plasma during blood sample storage and shipping as determined by digital PCR. J Clin Biochem 2013. in press.

18. Hayes DF, Smerage J: Is there a role for circulating tumor cells in the management of breast cancer? Clin Cancer Res 2008, 14:3646-3650.

19. de Bono JS, Scher HI, Montgomery RB, Parker C, Miller MC, Tissing H, Doyle GV, Terstappen LW, Pienta KJ, Raghavan D: Circulating tumor cells predict survival benefit from treatment in metastatic castration-resistant prostate cancer. Clin Cancer Res 2008, 14:6302-6309.

20. Cohen SJ, Punt CJ, lannotti N, Saidman BH, Sabbath KD, Gabrail NY, Picus J, Morse M, Mitchell E, Miller MC, Doyle GV, Tissing H, Terstappen LW, Meropol $\mathrm{NJ}$ : Relationship of circulating tumor cells to tumor response, progression-free survival, and overall survival in patients with metastatic colorectal cancer. J Clin Oncol 2008, 26:3213-3221.

21. Naoe M, Ogawa Y, Morita J, Omori K, Takeshita K, Shichijyo T, Okumura T, Igarashi A, Yanaihara A, Iwamoto S, Fukagai T, Miyazaki A, Yoshida H: Detection of circulating urothelial cancer cells in the blood using the cell search system. Cancer 2007, 109:1439-1445.

22. Okumura Y, Tanaka F, Yoneda K, Hashimoto M, Takuwa T, Kondo N, Hasegawa S: Circulating tumor cells in pulmonary venous blood of primary lung cancer patients. Ann Thorac Surg 2009, 87:1669-1675.

23. Steen S, Nemunaitis J, Fisher T, Kuhn J: Circulating tumor cells in melanoma: a review of the literature and description of a novel technique. Proc (Bayl Univ Med Cent) 2008, 21:127-132.

24. Parkinson DR, Dracopoli N, Petty BG, Compton C, Cristofanilli M, Deisseroth A, Hayes DF, Kapke G, Kumar P, Lee JS, Liu MC, McCormack R, Mikulski S, Nagahara L, Pantel K, Pearson-White S, Punnoose EA, Roadcap LT, Schade AE, Scher HI, Sigman CC, Kelloff GJ: Considerations in the development of circulatingtumor cell technology for clinical use. J Trans/ Med 2012, 10:138-148.

25. Sieuwerts AM, Kraan J, Bolt J, van der Spoel P, Elstrodt F, Schutte M, Martens JW, Gratama JW, Sleijfer S, Foekens JA: Anti-epithelial cell adhesion molecule antibodies and the detection of circulating normal-like breast tumor cells. J Natl Cancer Inst 2009, 101:61-66.

26. Srinivasan $M$, Sedmak $D$, Jewell $S$ : Effect of fixatives and tissue processing on the content and integrity of nucleic acids. Am J Pathol 2002, 161:1961-1971.

27. Das K, Wigginton S, Basiaga S, Williams T, Fernando MR: Effects of a novel cell stabilizing reagent on DNA amplification by PCR as compared to traditional stabilizing reagents. Acta Histochem 2014, 116:55-60.

doi:10.1186/1475-2867-14-23

Cite this article as: Qin et al: Stabilization of circulating tumor cells in blood using a collection device with a preservative reagent. Cancer Cell International 2014 14:23. 